\title{
Papillary muscle sandwich plasty for ischemic mitral regurgitation: A new simple technique
}

\author{
Susumu Ishikawa, MD, Keisuke Ueda, MD, Akio Kawasaki, MD, Kazuo Neya, MD, and Haruo Suzuki, MD, Tokyo, Japan
}

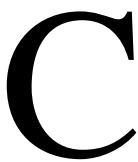
hronic ischemic mitral regurgitation (IMR) is recognized as functional regurgitation and a common cause of congestive heart failure caused by the myocardial infarction remodeling process. IMR is a strong predictor of poor outcomes in patients with ischemic cardiomyopathy.

Various types of mitral valve repair (MVR) techniques, such as annuloplasty, ${ }^{1}$ the edge-to-edge technique, ${ }^{2}$ and chordal cutting, have been reported. However, these procedures have yet to result in clearly improved patient outcomes, and the best surgical intervention is still controversial. Therefore the development of new techniques is necessary for better results in patients with IMR. Conventional MVR procedures, such as edge-to-edge repair or repair with an artificial chordae with an undersized ring were original

From the Department of Surgery, Cardiovascular Division, Teikyo University School of Medicine, Tokyo, Japan.

Received for publication Sept 17, 2007; revisions received Dec 20, 2007; accepted for publication Dec 27, 2007.

*Address for reprints: Susumu Ishikawa, MD, Cardiovascular Division, Department of Surgery, Teikyo University School of Medicine, 2-11-1 Kaga, Itabashi, Tokyo 173-8605, Japan (E-mail: ishikawa@med.teikyo-u.ac.jp).

J Thorac Cardiovasc Surg 2008;135:1384-6

$0022-5223 / \$ 34.00$

Copyright $\odot 2008$ by The American Association for Thoracic Surgery doi:10.1016/j.jtcvs.2007.12.034 options; however, satisfactory results were not obtained because of recurrent mitral regurgitation and late death. In this article we introduce our new simple procedure, the so-called sandwich plasty.

\section{Clinical Summary}

Sandwich plasty is usually performed through a left atrial incision under cardiac arrest. However, in some patients who require a left ventriculoplasty, the mitral valve can be approached through a left ventricular incision. Sandwich plasty consists of 2 procedures. The first procedure is the papillary muscle head approximations of the anterior and posterior mitral valve leaflets to achieve coaptation of the 2 leaflets. At the anterolateral commissural portion, a Teflonpledgeted 3-0 Ticron suture with a double-armed needle is passed through the papillary muscle head of the posterior leaflet and through the papillary muscle head of the anterior leaflet, reinforced with another Teflon patch. The same approximation suture is made at the posteromedian commissural portion (Figure 1). The second procedure is mitral annuloplasty with an exactly sized CarpenterEdwards Physio-ring (Figure 2). Transesophageal echocardiograms before and after sandwich plasty are presented in Figure 3.

\section{Discussion}

The cause of IMR is complicated because IMR results from a variable combination of annular dilatation and remodeling of the subvalvular apparatus. Although annular dilatation can be effectively treated, methods for addressing subvalvular remodeling have not
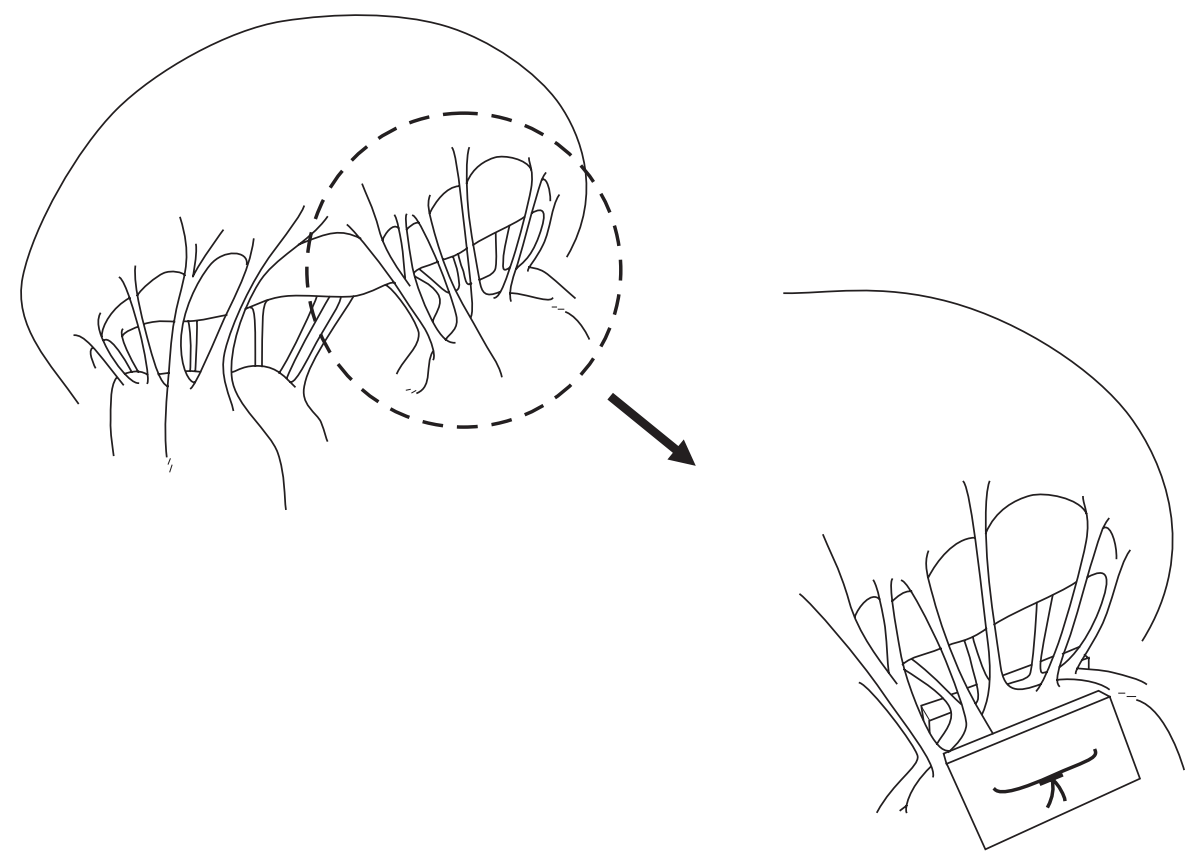

Figure 1. Schema of papillary muscle plication. A Teflon-pledgeted 3-0 Ticron suture is passed through the heads of the papillary muscles of the anterior leaflet and posterior leaflet at the posteromedian commissural portion, and bases of the chordae of the anterior and posterior leaflets are fixed. 

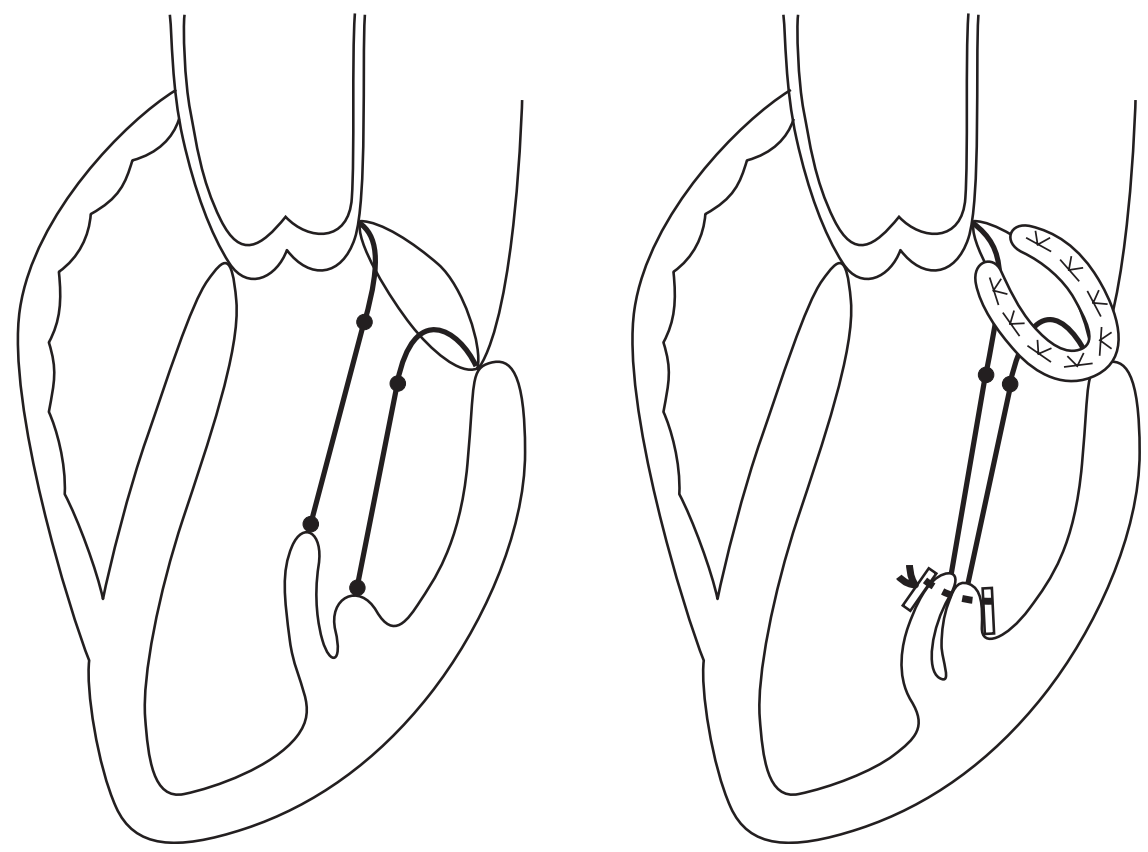

Figure 2. Schematic representation of sandwich plasty. Direction of chordae is corrected by papillary muscle placation, and ring annuloplasty keeps the sufficient coaptation zone.

been standardized. The importance of papillary muscle displacement caused by left ventricular dilatation has been recently recognized, and several procedures for papillary muscle repositioning with or without left ventriculoplasty have been reported. ${ }^{3,4}$ The aim of sandwich plasty is reduction of the tethering effect by fixing 2 heads of the papillary muscle connecting to the chordae of both the anterior and posterior leaflets. The advantage of sandwich plasty is the simplicity of the procedure, which is similar to that of edge-toedge repair. Hvass and colleagues ${ }^{5}$ also reported a simple and new procedure named the papillary muscle sling method, which created the close contact of both papillary muscles with a polytetrafluoroethylene* tube sling.

After the fixation of papillary muscles, leakage of the valve usually disappears because of the increase of the coaptation zone in an arrested heart. Menicanti and associates ${ }^{3}$ report the papillary muscle imbrication procedure without a mitral ring. However, we think an annular ring should be used to maintain a sufficient coaptation zone on a beating heart and to prevent further annular dilatation. We usually use an exactly sized ring, but an undersized ring might be selected if the coaptation of leaflets are not sufficient after papillary muscle plication. In this procedure we sometimes experience a slight difficulty in viewing the head of the papillary muscle of the anterior leaflet; however, this problem can be resolved by means of slight retraction of the chordae connecting to the anterior leaflet. According to our preliminary study, the late recurrence rate of mitral regurgitation was significantly less with sandwich plasty $(\mathrm{n}=22)$ compared with that after conventional MVR ( $\mathrm{n}=23 ; 4 \%$ vs $15 \%$ per patient per year). Patients' characteristics and operative results of sandwich plasty are presented in Table 1.

* Gore-Tex tube sling, registered trademark of W. L. Gore \& Associates, Inc, Newark, Del.
TABLE 1. Patients' characteristics and operative results of papillary muscle sandwich plasty
No. of patients

Male/female sex

Age $(y)^{*}$

Preoperative echocardiography

Left ventricular geometry

Diastolic diameter $(\mathrm{mm})^{*}$

Systolic diameter $(\mathrm{mm})^{*}$

Fractional shortening $(\%)^{*}$

Ejection fraction $(\%)^{*}$

Mitral valve

Annular dimension $(\mathrm{mm})^{*}$

Tenting height $(\mathrm{mm})^{*}$

Mitral regurgitation by echocardiography $\dagger$

Preoperative

Postoperative

Follow-up
22

$15 / 7$

$68 \pm 10(47-82)$

$53 \pm 6(41-61)$

$43 \pm 7(30-53)$

$40 \pm 10(24-66)$

$29 \pm 2(24-34)$

$12 \pm 3(7-16)$

$0 / 0 / 13 / 9$

$21 / 1 / 0 / 0$

$20 / 1 / 1 / 0$
$20 \pm 5(9-33)$

*Mean \pm standard deviation. $\dagger$ Non-trivial/mild/moderate/severe.

In conclusion, sandwich plasty is considered to be a simple and effective procedure; however, late follow-up results are indispensable when reviewing this procedure, which might improve the prognosis of patients with ischemic heart failure.

\section{References}

1. McGee EC, Gillinov AM, Blackstone EH, Rajeswaran J, Cohen G, Najam F, et al. Recurrent mitral regurgitation after annuloplasty for functional ischemic mitral regurgitation. J Thorac Cardiovasc Surg. 2004; 128:916-24. 

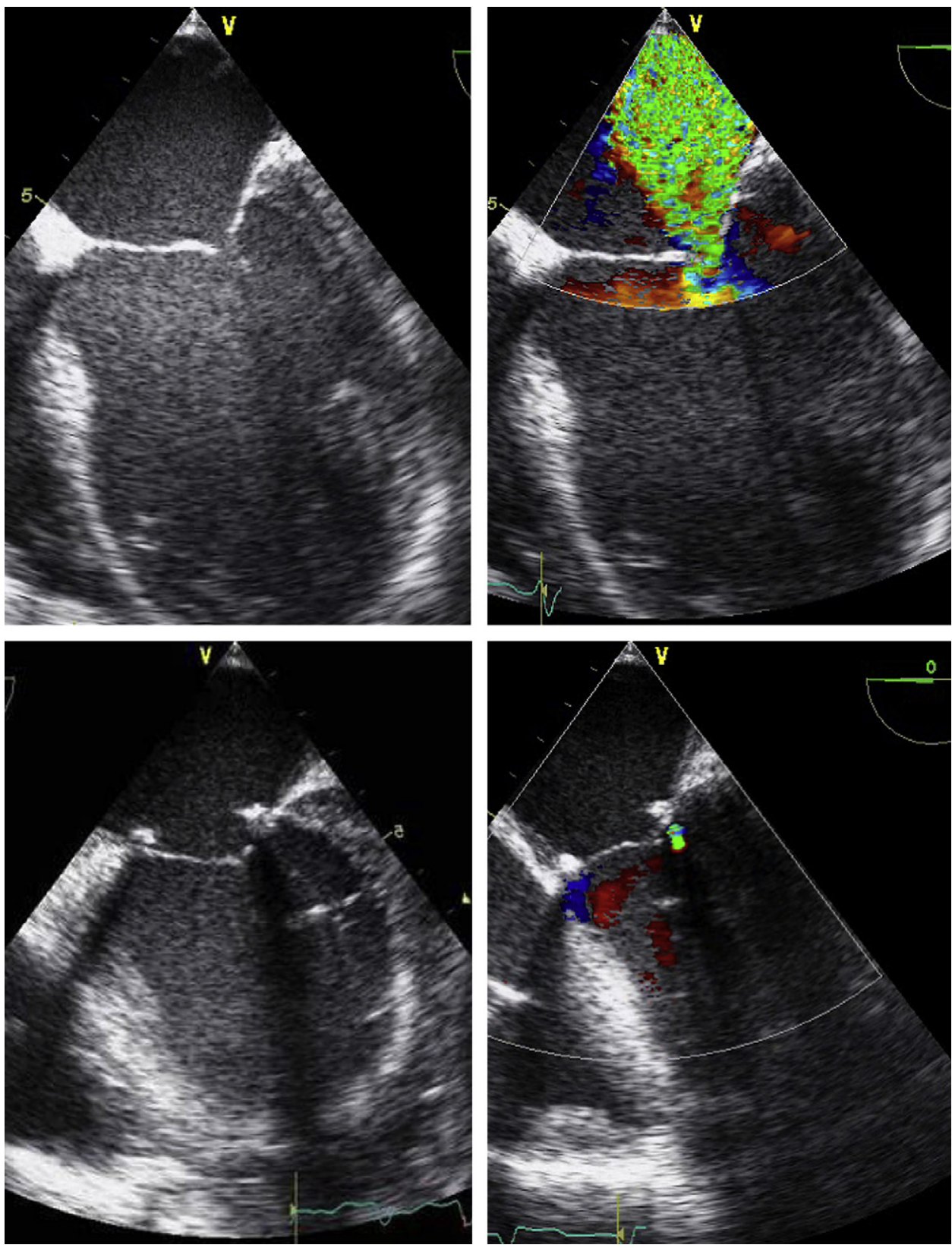

Figure 3. Transesophageal echocardiograms before (top) and after (bottom) sandwich plasty. Severe mitral regurgitation disappeared after sandwich plasty because of better coaptation of the 2 leaflets.

2. De Bonis M, Lapenna E, La Canna G, Ficarra E, Pagliaro M, Torracca L, et al. Mitral valve repair for functional mitral regurgitation in end-stage dilated cardiomyopathy: role of the "edge-to-edge" technique. Circulation. 2005;112(suppl):I402-8.

3. Menicanti L, Di Diano M, Frigiola A, Buckberg G, Santambrogio C, Rauncci M, et al. Ischemic mitral regurgitation: intraventricular papillary muscle imbrication without mitral ring during left ventricular restoration. $J$ Thorac Cardiovasc Surg. 2002;123:1041-50.
4. Langer F, Schafers HJ. RING plus STRING: Papillary muscle repositioning as an adjunctive repair technique for ischemic mitral regurgitation. J Thorac Cardiovasc Surg. 2007;133:247-9.

5. Hvass U, Tapia M, Baron F, Pouzet B, Shafy A. Papillary muscle sling: a new functional approach to mitral repair in patients with ischemic left ventricular dysfunction and functional mitral regurgitation. Ann Thorac Surg. 2003;75:809-11. 